\title{
The Effectiveness of Mindfulness Training Techniques on Stress, Anxiety, and Depression of Depressed Patient
}

\author{
Merfat. M. Atia*, Lobna E. Sallam \\ Department of Psychiatric Mental Health Nursing, Faculty of Nursing, Shebin El-kom, Menufia University, Egypt \\ *Corresponding author: Mervatatia@yahoo.com
}

Received November 02, 2019; Revised December 21, 2019; Accepted December 29, 2019

\begin{abstract}
Depression remains one of the world's most urgent health problems, affecting an estimated 350 million people. Mindfulness is effective for people suffering from critical depressive symptoms. The aim of this study was to evaluate the effectiveness of mindfulness training techniques on stress, anxiety, and depression of depressed patients. Design: - Quasi-experimental design (one group pretest-posttest design) was used to achieve the aim of the study. Setting: - The study was conducted at the Psychiatric Hospital in Tanta and The Psychiatric and Addiction Treatment Hospital in Met-Khalf, Menoufia governorate, Egypt. Sample: -A Purposive sample (34) depressed patients that were diagnosed by psychiatrists according to DSM5 were selected; in the chosen setting inpatient clinics. Tools: Data were collected using the depression, anxiety and stress scale. Results: The results revealed that there is a highly statistically significant reduction in stress, anxiety, and depression mean score level among the study group after mindfulness training techniques than before; where $\mathrm{p}$-value $(\mathrm{p}=0.001)$. Also, there is a statistically significant positive correlation between stress and depression level of study group before and after mindfulness training techniques where $\mathrm{p}$-value $(\mathrm{p}=0.015,0.013)$, respectively. Conclusion: The implementation of mindfulness training techniques with depressed patients has a positive effect on reducing stress, anxiety, and depression levels. Recommendation: Application of mindfulness training techniques for all patients with depression to reduce their stress, anxiety, and depression levels.
\end{abstract}

Keywords: depression, mindfulness techniques, depressed patients

Cite This Article: Merfat. M. Atia, and Lobna E. Sallam, "The Effectiveness of Mindfulness Training Techniques on Stress, Anxiety, and Depression of Depressed Patient.” American Journal of Nursing Research, vol. 8, no. 1 (2020): 103-113. doi: 10.12691/ajnr-8-1-11.

\section{Introduction}

Depression is a universal public health problem, affecting an estimated 350 million people global [1]. "Depression is a common mental disorder, characterized by persistent sadness and a loss of interest in activities that you normally enjoy, accompanied by an inability to carry out daily activities, for at least two weeks” [2]. Mindfulness defined as "an awareness that emerges through paying attention on purpose, in the present moment, and non-judgmental to things as they are being mindful in our everyday life, in our actions and our thoughts is something that can be trained like any other skill [3]. The simplest definition of mindfulness "is paying attention to one's experience in the present moment". "It involves observing thoughts and emotions from moment to moment without judging or becoming caught up in them". During a practice session; " when the mind wanders, the mediator ideally takes note of where it goes, and calmly returns to the moment at hand, perhaps focusing on the breath, bodily sensations or a simple yoga move" [4]. Also, "Mindfulness is even effective for people dealing with the most critical of depressive symptoms: suicidal ideation or thoughts of suicide”. In chronically depressed patients with suicidal thoughts, mindfulness was more effective than treatment as usual in reducing these thoughts [5]. [6], has revealed the valuable effects of mindfulness training on physical and psychological health and well-being. Moreover, the research proposes that "mechanisms that are responsible for valuable effects of mindfulness training involve not only relaxation, but also shifts in cognitive patterns, emotional processing, biology, and behavior that interact to create improvements in health, quality of life, and ability to engage in meaningful relationships with others". Studies in the basic sciences provided important evidence that mindfulness training might cause significant alterations in brain functioning and structures that are associated with improved emotional well-being in short and long term [7].

\section{Significance of the Study}

Depression is not only the most common mental illness; it's also one of the most tenacious diseases. Up to 80 percent of people who experience a major depressive episode may relapse. Drugs may lose their efficiency over time if they work at all [4]. Also, major depressive disorder (MDD) is "a prevalent psychiatric disorder 
associated with various prognosis, chronic course, and duration of illness with decreased quality of life” [8]. A study was conducted by [9] found that "the prevalence of depressive symptoms was $28.6 \%$ and that of depressive disorders was $11.3 \%$." Also, "a descriptive study was conducted on a representative randomized sample from 27sites in Dakahlia Governorate, Egypt by [10], their results displayed that "a prevalence of $10.6 \%$ of common mental disorders with significant disability and effect on the quality of life (QOL); the most frequent diagnosis is the dysthymic disorder (3.4\%), followed by generalized anxiety disorder (1.7\%), major depressive disorder (1.5\%) and obsessive-compulsive disorder (1.4\%)". Moreover, [11] conducted "a study to estimate the prevalence of depressive symptoms among 311 medical school students in Egypt; they found that "the prevalence of depression was $28.3 \%$ ".

Mindfulness has long been considered effective complementary management for depression. [12]; their result showed that "mindfulness reduced depressive symptoms, anxiety, and stress in college students, as well as increasing self-compassion when compared with yoga alone". Also, "there has been a growing interest in applying mindfulness into Western medical treatments in recent years, due to the evidence-based research of its benefits of treating patients suffering from for example depression, anxiety, and chronic pain" [13]. For those reasons "a psychiatric nurse should be trained in mindfulness techniques to offer specific guided-techniques including Attention to Breathing, Awareness of Thoughts, Awareness of the Body, and Guided Imagery". Also, "the psychiatric nurse worked collaboratively with the participant to investigate and decide which guided-technique might be most helpful to them". Therefore, the purpose of this study was to evaluate the effectiveness of mindfulness training techniques on stress, anxiety, and depression of depressed patients.

\section{Operational Definitions}

Mindfulness is "the psychological process of purposely bringing one's attention to experiences occurring in the present moment without judgment, which one can develop through the practice of meditation and through other training”. [14-17]

Mindfulness training techniques are operationally defined as" training techniques that given to depressed patients to enable them to improve their health and overall quality of life, reduce their anxiety and depression symptoms, increase their concentration, and achieve stronger ability to cope more effectively with day-to-day stresses". [18]

Depression is defined as "a state that is characterized by much more than an appropriate feeling of sadness, despair, loneliness, low self-esteem \& self-reproach. Accompanying signs \& symptoms include persistent, debilitating and change how they interact with the world, withdrawal from social contact, and vegetative states such as loss of appetite and insomnia”. [19-22]

Anxiety is "a state of mind which creates depending on natural stimulants that are seen by the individuals as being unsafe or threatening and have unpleasing impacts”. [23-28]
Stress: In a medical or biological context stress is "a physical, mental, or emotional factor that causes bodily or mental tension. Stresses can be external (from the environment, psychological, or social situations) or internal (illness, or from a medical procedure). Stress can initiate the "fight or flight" response, a complex reaction of neurologic and endocrinologic systems”. [29]

The Depression Anxiety Stress Scale (DASS) "was built-up with somatic items excluded to evaluate this problem specifically. It is, thus, likely to provide clinicians with an exact appraisal of their patient's symptoms of anxiety, depression, and stress”. [30-34]

\section{Subjects and Methods}

\subsection{The Purpose of the Study}

The purpose of this study was to evaluate the effectiveness of mindfulness training techniques on stress, anxiety, and depression of depressed patients.

\subsection{Research Hypothesis}

Implementation of mindfulness training techniques on depressed patients will reduce stress, anxiety, and depression levels.

\subsection{Research Design}

A quasi-experimental design (one group pre-posttest design) was used to accomplish the purpose of the study.

\subsection{Research Setting}

The study was conducted at the Psychiatric Hospital in Tanta and The Psychiatric and Addiction Treatment Hospital in Met-Khalf, Menoufia governorate, Egypt.

\subsection{Subjects}

-A Purposive sample (34) was nominated in the chosen setting inpatient clinics.

\subsubsection{Inclusion Criteria}

- "Patients whose were diagnosed by psychiatrist as depressed patients.

- "Patient aged from 20- 60 years under treatment therapy"

- "Both sex".

- "Alert and approve to participate in the study"

\subsubsection{Exclusion Criteria}

"Patients who were being treated for psychosis, bipolar disorder, or major substance misuse were excluded”.

\subsection{Tools of the Study}

Two tools were used in this study:-

1- Questionnaire for socio-demographic data of the patients such as age, sex, occupation, level of education and family history of mental illness, compliance of medication. 
2- Depression, Anxiety and Stress Scale (DASS):

The Depression, Anxiety and Stress Scale (DASS) by [35] translated into Arabic and tested for content validity by [36]. Reliability of three scales considered adequate and test-retest reliability is likewise considered adequate with.71 for depression, .79 for anxiety, and .81 for stress. It consisted of a 42- questionnaire which includes three self-report sub-scales designed to measures the negative emotional states of depression, anxiety, and stress. Each of the three subscales contains 14 items, depression (14 items), anxiety (14 items), stress (14 items) divided into subscales of 2-5 items with similar content. The depression scale assesses dysphoria, hopelessness, and devaluation of life, self- deprecation, and lack of interest, Anhedonia, and inertia. The anxiety scale assesses autonomic arousal, skeletal muscle effects, situational anxiety, and subjective experience of anxious effect. The stress scale (items) is sensitive to levels of chronic nonspecific arousal; it assesses difficulty relaxing, nervous arousal, and being easily upset, irritable and impatient. Scores for depression, anxiety, and stress are calculated by summing the scores for the relevant items. The total score ranges from 14-42. The higher score indicates negative emotional status.

\subsubsection{Reliability of the Tools}

Reliability was applied by the researcher for testing the internal consistency of the tool, by administration of the same tools to the same subjects under similar conditions on one or more occasions. Answers from repeated testing were compared (Test-re-test reliability).

\subsubsection{Validity of the Tools}

They were tested for content validity by jury of five experts in the field of Psychiatric Mental Health Nursing and Pediatric nursing specialty to ascertain relevance and completeness

\subsection{Procedure}

An administrative approval: It was obtained from the dean of faculty of nursing and the director of The Psychiatric Hospital in Met-Khalf and psychiatric hospital in Tanta after explanation for the purpose of the study and the questionnaire used in the study by the researcher.

\section{Ethical consideration:}

An approval of the ethical and rehearsal research committee of the faculty of Nursing, Menoufia University, Egypt was obtained. Throughout the initial interview, the study purpose and procedures were clarified and the written consent was obtained from the participants' .The subjects were assured that all information would be confidential to assure the confidentiality of the participants. Participants were secure that their participation in the study was voluntary and that they could withdraw from the study or can refuse to participate in the study at any time. It was explained that there were no costs to participate in the study.

A Pilot study: Before starting data collection; a pilot study was carried out on (5) patients, to assess the clarity, applicability and time needed to fill the tools. The necessary modifications were done as revealed from the pilot study. The sample of the pilot study was excluded from the total sample of the study.

Data collection:- The data were collected from the inpatient clinics at The Psychiatric Hospital in Tanta and The Psychiatric and Addiction Treatment Hospital in MetKhalf, Menoufia governorate, Egypt; using the abovementioned tools for data collection. The study was carried out in the period from March 2019 to May 2019. The researcher collected the data during the morning at two days/week from $10 \mathrm{AM}$ to $12 \mathrm{AM}$. The entire subjects who meet the inclusion criteria were included in the study, the subjects were divided into 5 groups; each of them consisted of 7 patients and only one group contains 6 patients. The period of implementation was 2 months. Implementation of the study passed into three phases: (pre-assessment phase, implementation phase, and postassessment phase).

\subsubsection{Pre Assessment Phase (Measure1)}

A comfortable, private place was chosen for the interview. Orientation was done about the researcher's name, purpose, significance, content of the study. Subjects were interviewed individually at their rooms where preassessment was done using the depression, anxiety and stress scale (DASS) and socio-demographic questionnaire.

\subsubsection{Implementation Phase}

Mindfulness training techniques aimed at reducing stress, anxiety, and depression of depressed patients. The intervention group was met for eight consecutive weekly sessions that lasted approximately $2 \mathrm{hr}$. The researcher led the group and the co-leader recorded the sessions. This mindfulness training techniques had a set of specific objectives for each of the 8 sessions. This was achieved through several teaching methods such: Data show, video, pictures, and role play. Demonstration \& re-demonstration under researchers' supervision and then the patients apply mindfulness techniques alone.

The content of the mindfulness training techniques sessions was as follows:

1) Introduction about the concept and nature of mindfulness techniques.

2) Principles and practical instruction for using mindfulness techniques.

3) Mindfulness techniques (body scan, A Three-Minutes Mindfulness, Mindfulness breathing, Mindfulness of thoughts, Mindfulness meditation and Mindfulness eating).

Each session focused on mindfulness techniques that could be used in everyday life. One session is lecture on the nature, concept of mindfulness techniques and principles for mindfulness practice provided by the researcher, seven sessions in mindfulness techniques.

A short description of the mindfulness techniques employed in the study are explained below.

\section{Body scan}

DESCRIPTION: - The researcher asked the patient to sit comfortably with his/her back straight. A typical body scans run through each part of the body, paying special attention to the way each area feels. The scan usually moves systematically through the body, e.g. starting from 
the feet and moving upwards. The patient was instructed to be aware of any sensations, emotions or thoughts associated with each part of his/her body. Take some few deep breaths. - Breathe in through his/her nose, 1-2-3. - Breathe out through his/her mouth, 3-2-1. (Silence) - Notice his/her feet on the floor, notice the sensations of his/her feet touching the floor. Is it heavy or light? Cold or warm, and so on throughout each part of his/her body. It is OK if the patient did not notice anything at all, just observe without judgment [37].

\section{2- A Three -Minutes Mindfulness:-}

\section{DESCRIPTION:}

1. First minute: Awareness. The researcher asked the patient to become aware of his/her body. Notice any bodily sensations, but without the need to change what is being observed. Now become aware of his/her emotions. Notice how He/ She were feeling at the moment. And now become aware of his/her thoughts.

2. Second minute: Focus on the breath. The researcher asked the patient to bring his/her attention to your breathing. Feel the whole of his/her in- and out-breath for about a minute. If you can, feel his/her breathing down in his/her belly. Gather his/her attention into his/her breath and use his/her breathe as a stable place to rest his/her focus.

3. Third minute: The researcher asked the patient to widen attention again to include the body as a whole, feeling all the sensations in his/her body, with a sense of kindness and curiosity if $\mathrm{He} / \mathrm{She}$ can. Allow space for all sensations to just be there [37]

\section{3- Mindfulness breathing:-}

DESCRIPTION: The researcher asked the patient to sit comfortably with his/her back straight brings attention to his/her body. Close his/her eyes and gently guide his/her attention to the natural rhythm of your breath in his/her chest and belly. The patient was instructed to simply notice the breath as $\mathrm{He} / \mathrm{She}$ breathe in... and out. Since the air passing from the chest through his/her nose and mouth as he/she breathes in ....and out. Continue to notice his/her breathing with a sense of kindness and gentle allowing. There's nothing to do except notice his/her breath. If she/he finds his/her mind wandering or she/he feels distracted, just kindly notice that, and return his/her attention to the rhythm of his/her breath and the rising and falling of his/her chest and belly. Continue this practice of kind observation for as long as you wish- just noticing his/her breath doing its thing. Continue practicing the mindfulness breathing for five to ten minutes. The researcher instructed patients to practice this skill throughout the day [37].

\section{4-- Mindfulness of thoughts:-}

DESCRIPTION: The researcher asked the patient to sit comfortably with his/her back straight; bring his/her awareness to his/her breath. Be aware of his/her breath as it fills his/her lungs and expands his/her abdomen, and then leaves his/her body.2) Now slowly allow his/her self to notice any thoughts that come into his/her head as he/she was aware of his/her breathing. 3) Take notice, pay attention, and accept those thoughts, without making a judgment on them. 4) watch his/her thoughts as they rise and fall into his/her awareness, she/he may struggle with this as it is easy and tempting to engage with his/her thoughts. If she/he notices his/herself engaging with thoughts, just bring his/her attention back to being the observer of his/her thoughts rather than an examiner. Engaging with his/her thoughts is what we normally or often practice so, don't despair if this happens [37].

\section{5- Mindfulness meditation}

DESCRIPTION: The researcher asked the patient to:

1. Find a quiet and comfortable place. Wear comfortable clothing. Sit in a chair or on the floor with his/her head, neck, and back straight but not stiff.

2. Try to put separately all thoughts of the past and the future and focus on the present.

3. Relax. Bring his/her attention to his/her breath or the sensations in his/her body.

4. Be there for a few moments. Become aware of his/her breath, attuning to the sensation of air moving in and out of his/her body as $\mathrm{He} /$ She breathe. Feel his/her belly rise and fall and the air enter his/her nostrils and leave his/her mouth. Pay attention to the way each breath changes and is different.

5. Watch every thought come and go, whether it is a worry, fear, anxiety, or hope. When thoughts come up in his/her mind, don't ignore or suppress them. Simply note them, remain calm, and focus on his/her breathing.

6. If $\mathrm{He} / \mathrm{She}$ find his/her self-getting carried away in his/her thoughts, observe where his/her mind went off to, without judgment, and just return to his/her breathing.

7. As the time comes to a close, sit for a minute or two, becoming aware of where $\mathrm{He} / \mathrm{She}$ were. Get up gradually [16].

\section{6-Mindfulness eating:-}

DESCRIPTION: The researcher asked the patients to bring their attention to a raisin (or similar object), observing it carefully as if they had never seen one before. Tell patients to pick up the raisin and feel its texture between their fingers and notice its colors. Inform them to be aware of any thoughts they might be having about the raisin. Note any thoughts or feelings of liking or disliking raisins if they come up while they are looking at it. Then lift the raisin to their nose and smell it for a while and finally, with awareness, bring it to their lips, being aware of their arm moving their hand to position it correctly and of their mouth salivating as the mind and body anticipate eating. The researcher told patients to take the raisin into their mouth and chew it slowly, experiencing the actual taste of the raisin. Hold it in their mouth. When they feel ready to swallow, watch the impulse to swallow as it comes up [37]. 


\subsubsection{Post Assessment Phase (Measure2)}

Evaluation was done using the depression, anxiety and stress scale (DASS) to assess level of depression, anxiety and stress for depressed patients.

\section{Results}

Table 1 shows that half of the study subject(50\%) were in age group (30-40y), and (52.9\%, 52.9\% and 52.9\%), were female, had not any children and not compliance with medication, nearly one-third of the study subject (35.3\%,35.3\%) were read \& write and in university educational levels, slightly above half of the study subject (52\%) were single, most of study subjects (79.4\%) were unemployed, nearly one-third of the study subjects (35.3\%) had depression for more than five years, more than half of the study subject (58.8\%) had not family history of disease.

Table 2 revealed that there was a highly statistically significant reduction in stress, anxiety and depression mean score level from $(27.1 \pm 4.37)$ to $(18.8 \pm 3.14)$ for stress levels, from (24.9 \pm 4.34$)$ to $(16.6 \pm 2.42)$ for anxiety level and from (27.8 \pm 3.85$)$ to $(20.2 \pm 3.31)$ for depression level among study group after mindfulness training techniques than before, where $\mathrm{p}$ value $(\mathrm{p}=0.001)$.

Table 3 displayed that there was a statistically significant positive correlation between depression and stress levels of study group before and after intervention where $\mathrm{p}$ value $(\mathrm{p}=0.015,0.013$ ) respectively. Regarding correlation between depression and anxiety level, there was a statistically significant positive correlation between depression and anxiety level of study group before intervention where $\mathrm{p}$ value $(\mathrm{p}=0.019)$.

Table 4 revealed that there was a highly statistically significant relation between stress level and age, marital status, diseases duration / years, compliance to medication and children number of the study group after mindfulness training techniques. Where $(\mathrm{p}=0.006,0.001,0.003,0.009$ and 0.001 respectively)

Table 5 indicated that there was a highly statistically significant relation between anxiety level and (gender, children number) after mindfulness training techniques, where ( $\mathrm{p}=0.004,0.008$ respectively) and there was statistically significant relation between anxiety level and (marital status, compliance to medication) of the study group after mindfulness training techniques where ( $p=0.012,0.011$ respectively).

Table 6 presented that there was no statistically significant relation between depression level and socio demographic characters of the studied group as in age, gender, educational level, marital state, occupation, family history, number of children. Also, there was no statistically significant relation between depression level and compliance to medication. While there was statistically significant relation between depression level and diseases duration / years of the studied group after mindfulness training techniques.

Table 1. Socio demographic characters of the studied group $(N=34)$

\begin{tabular}{|c|c|c|c|}
\hline \multirow{2}{*}{\multicolumn{2}{|c|}{ Socio demographic characters }} & \multicolumn{2}{|c|}{$\begin{array}{c}\text { Study group } \\
(\mathrm{N}=34)\end{array}$} \\
\hline & & \multirow{2}{*}{$\begin{aligned} \text { No. } \\
12\end{aligned}$} & \multirow{2}{*}{$\begin{array}{c}\% \\
35.3\end{array}$} \\
\hline & $20-<30$ & & \\
\hline Age / years & $30-40$ & 17 & 50.0 \\
\hline & $50-60$ & 5 & 14.7 \\
\hline \multirow{2}{*}{ Gender } & Male & 16 & 47.1 \\
\hline & Female & 18 & 52.9 \\
\hline \multirow{6}{*}{ Educational level } & Illiterate & 4 & 11.8 \\
\hline & Read and write & 12 & 35.3 \\
\hline & Primary education & 2 & 5.90 \\
\hline & Preparatory education & 3 & 8.80 \\
\hline & Secondary education & 1 & 2.90 \\
\hline & University & 12 & 35.3 \\
\hline \multirow{3}{*}{ Marital state } & Single & 18 & 52.9 \\
\hline & Married & 12 & 35.3 \\
\hline & Divorced & 4 & 11.8 \\
\hline \multirow{3}{*}{ Occupation } & Employed & 3 & 8.80 \\
\hline & Unemployed & 27 & 79.4 \\
\hline & Worker & 4 & 11.8 \\
\hline \multirow{4}{*}{$\begin{array}{l}\text { Diseases duration / } \\
\text { years }\end{array}$} & $<1$ year & 10 & 29.4 \\
\hline & $1-2$ years & 10 & 29.4 \\
\hline & $2-5$ years & 2 & 5.90 \\
\hline & $>5$ years & 12 & 35.3 \\
\hline \multirow{2}{*}{ Family history } & Yes & 14 & 41.2 \\
\hline & No & 20 & 58.8 \\
\hline \multirow{2}{*}{$\begin{array}{l}\text { Compliance to } \\
\text { medication }\end{array}$} & Yes & 16 & 47.1 \\
\hline & No & 18 & 52.9 \\
\hline \multirow{3}{*}{ Number of children } & $1-2$ child & 11 & 32.4 \\
\hline & 2 -3 child & 5 & 14.7 \\
\hline & No children & 18 & 52.9 \\
\hline
\end{tabular}


Table 2. Mean scores and SD of anxiety, stress and depression levels of studied group pre and post mindfulness training techniques $(\mathbf{N}=34)$

\begin{tabular}{|l|c|c|c|}
\hline \multirow{2}{*}{ Studied variables } & Pre-intervention & Post-intervention & \multirow{2}{*}{ Paired t-test } \\
\cline { 2 - 4 } & Mean \pm SD & Mean \pm SD & 25.4 \\
\hline Stress & $27.1 \pm 4.37$ & $18.8 \pm 3.14$ & $<\mathbf{0 . 0 0 1 * *}$ \\
\hline Anxiety & $24.9 \pm 4.34$ & $16.6 \pm 2.42$ & $<0.001 * *$ \\
\hline Depression & $27.8 \pm 3.85$ & $20.2 \pm 3.31$ & 21.5 \\
\hline
\end{tabular}

**High significant.

Table 3. Correlation between anxiety, stress and depression levels of studied group pre and post mindfulness training techniques $(\mathrm{N}=34)$

\begin{tabular}{|l|c|c|c|c|}
\hline \multirow{2}{*}{ Studied variables } & \multicolumn{2}{|c|}{ Pre-intervention Stress } & \multicolumn{2}{c|}{ Post-intervention Stress } \\
\cline { 2 - 5 } & $\mathbf{R}$ & P value & R value & 0.254 \\
\hline Anxiety & 0.294 & 0.091 & $\mathbf{0 . 4 2 3}$ & 0.147 \\
\hline Depression & $\mathbf{0 . 4 1 3}$ & $\mathbf{0 . 0 1 5 *}$ & Post-intervention Anxiety \\
\hline Studied variables & Pre-intervention Anxiety & 0.267 \\
\hline Depression & $\mathbf{0 . 4 0 2}$ & $\mathbf{0 . 0 1 9 *}$ & 0.126 \\
\hline
\end{tabular}

Table 4. Relation between stress level and socio demographic characters of the studied group after mindfulness training techniques $(\mathrm{N}=34)$

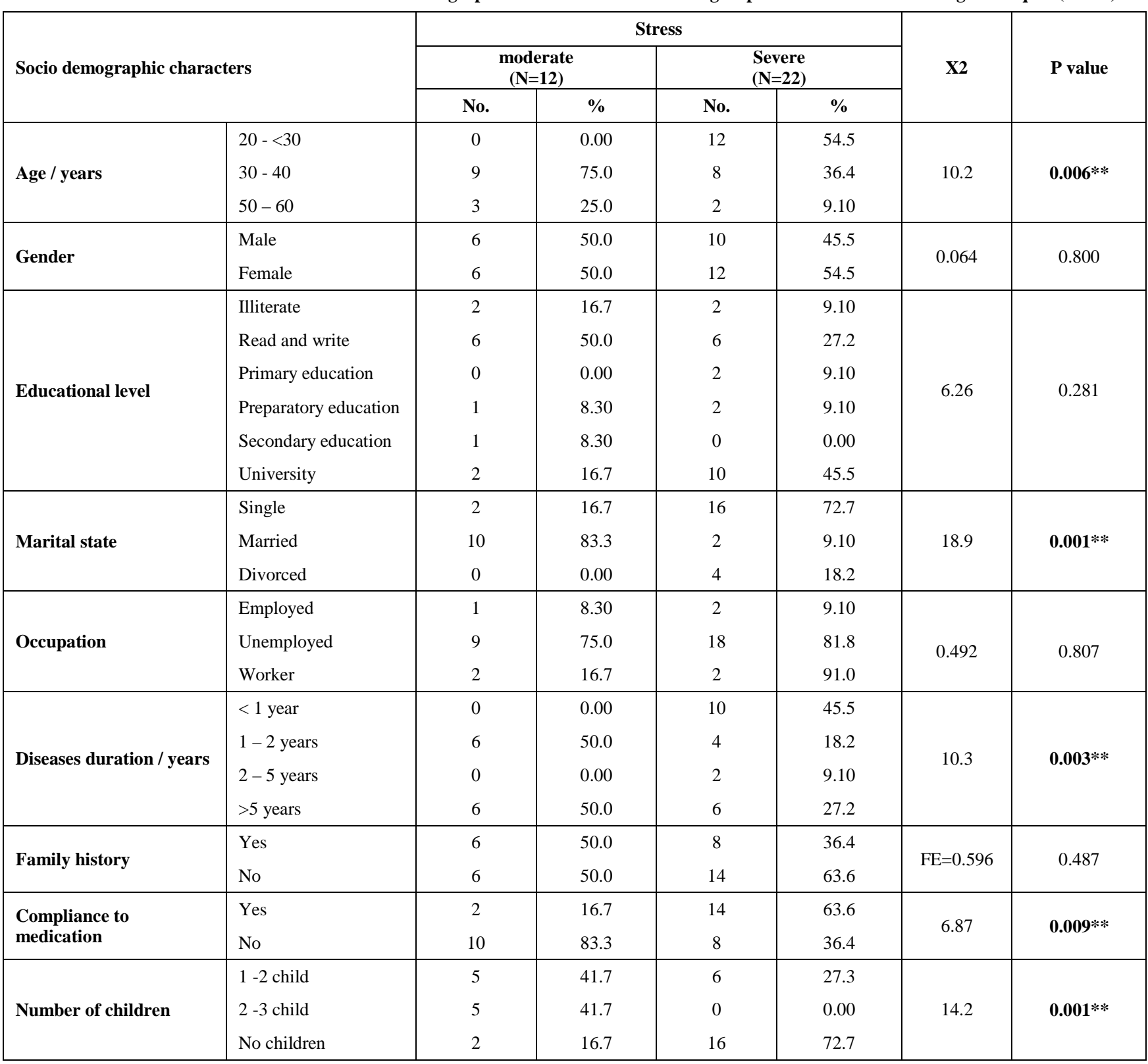

FE: Fisher exact test $* *$ High significant. 
Table 5. Relation between anxiety level and socio demographic characters of the studied group after mindfulness training techniques $(\mathrm{N}=34)$ :

\begin{tabular}{|c|c|c|c|c|c|c|c|}
\hline \multirow{2}{*}{\multicolumn{2}{|c|}{ Socio demographic characters }} & \multicolumn{4}{|c|}{ Anxiety } & \multirow{3}{*}{$\mathrm{X} 2$} & \multirow{3}{*}{$P$ value } \\
\hline & & \multicolumn{2}{|c|}{$\begin{array}{c}\text { Moderate } \\
(\mathrm{N}=6)\end{array}$} & \multicolumn{2}{|c|}{$\begin{array}{c}\text { Sever } \\
(\mathrm{N}=28)\end{array}$} & & \\
\hline & & No. & $\%$ & No. & $\%$ & & \\
\hline \multirow{3}{*}{ Age / years } & $20-<30$ & 0 & 0.00 & 12 & 42.9 & \multirow{3}{*}{4.21} & \multirow{3}{*}{0.122} \\
\hline & $30-40$ & 5 & 83.3 & 12 & 42.9 & & \\
\hline & $50-60$ & 1 & 16.7 & 4 & 14.2 & & \\
\hline \multirow{2}{*}{ Gender } & Male & 6 & 100 & 10 & 35.7 & $\mathrm{FE}=$ & \multirow[b]{2}{*}{$0.004 * *$} \\
\hline & Female & 0 & 0.00 & 18 & 64.3 & 8.19 & \\
\hline \multirow{6}{*}{ Educational level } & Illiterate & 2 & 33.3 & 2 & 7.10 & \multirow{6}{*}{11.0} & \multirow{6}{*}{0.050} \\
\hline & Read and write & 2 & 33.3 & 10 & 35.8 & & \\
\hline & Primary education & 0 & 0.00 & 2 & 7.10 & & \\
\hline & Preparatory education & 1 & 16.7 & 2 & 7.10 & & \\
\hline & Secondary education & 1 & 16.7 & 0 & 0.00 & & \\
\hline & University & 0 & 0.00 & 12 & 42.9 & & \\
\hline \multirow{3}{*}{ Marital state } & Single & 0 & 0.00 & 18 & 64.3 & \multirow{3}{*}{8.79} & \multirow{3}{*}{$0.012^{*}$} \\
\hline & Married & 4 & 66.7 & 8 & 28.6 & & \\
\hline & Divorced & 2 & 33.3 & 2 & 7.10 & & \\
\hline \multirow{3}{*}{ Occupation } & Employed & 1 & 16.7 & 2 & 7.10 & \multirow{3}{*}{4.18} & \multirow{3}{*}{0.124} \\
\hline & Unemployed & 3 & 50.0 & 24 & 85.8 & & \\
\hline & Worker & 2 & 33.3 & 2 & 7.10 & & \\
\hline \multirow{4}{*}{ Diseases duration / years } & $<1$ year & 0 & 0.00 & 10 & 35.7 & \multirow{4}{*}{4.64} & \multirow{4}{*}{0.200} \\
\hline & $1-2$ years & 2 & 33.3 & 8 & 28.6 & & \\
\hline & $2-5$ years & 0 & 0.00 & 2 & 7.10 & & \\
\hline & $>5$ years & 4 & 66.7 & 8 & 28.6 & & \\
\hline \multirow{2}{*}{ Family history } & Yes & 4 & 66.7 & 10 & 35.7 & $\mathrm{FE}=$ & \multirow[b]{2}{*}{0.202} \\
\hline & No & 2 & 33.3 & 18 & 64.3 & 1.95 & \\
\hline \multirow{2}{*}{ Compliance to medication } & Yes & 0 & 0.00 & 16 & 57.1 & \multirow[b]{2}{*}{6.47} & \multirow[b]{2}{*}{ 0.011* } \\
\hline & No & 6 & 100 & 12 & 42.9 & & \\
\hline \multirow{3}{*}{ Number of children } & $1-2$ child & 5 & 83.3 & 6 & 21.4 & \multirow{3}{*}{9.72} & \\
\hline & 2 -3 child & 1 & 16.7 & 4 & 14.3 & & $0.008 * *$ \\
\hline & No children & 0 & 0.00 & 18 & 64.3 & & 0.000 \\
\hline
\end{tabular}

FE: Fisher exact test **High significant *significant.

Table 6. Relation between depression level and socio demographic characters of studied group after mindfulness training techniques $(\mathrm{N}=34$ )

\begin{tabular}{|c|c|c|c|c|c|c|c|}
\hline \multirow{3}{*}{\multicolumn{2}{|c|}{ Socio demographic characters }} & \multicolumn{4}{|c|}{ Depression } & \multirow{3}{*}{$\mathrm{X} 2$} & \multirow{3}{*}{$P$ value } \\
\hline & & \multicolumn{2}{|c|}{$\begin{array}{c}\text { Moderate } \\
(\mathrm{N}=24)\end{array}$} & \multicolumn{2}{|c|}{$\begin{array}{c}\text { Sever } \\
(\mathrm{N}=10)\end{array}$} & & \\
\hline & & No. & $\%$ & No. & $\%$ & & \\
\hline \multirow{3}{*}{ Age / years } & $20-<30$ & 8 & 33.3 & 4 & 40.0 & \multirow{3}{*}{2.45} & \multirow{3}{*}{0.293} \\
\hline & $30-40$ & 11 & 45.8 & 6 & 60.0 & & \\
\hline & $50-60$ & 5 & 20.8 & 0 & 0.00 & & \\
\hline \multirow{2}{*}{ Gender } & Male & 10 & 41.7 & 6 & 60.0 & \multirow{2}{*}{$\mathrm{FE}=0.952$} & \multirow[b]{2}{*}{0.457} \\
\hline & Female & 14 & 58.3 & 4 & 40.0 & & \\
\hline \multirow{6}{*}{$\begin{array}{l}\text { Educational } \\
\text { level }\end{array}$} & Illiterate & 2 & 8.30 & 2 & 20.0 & \multirow{6}{*}{8.31} & \multirow{6}{*}{0.140} \\
\hline & Read and write & 8 & 33.3 & 4 & 40.0 & & \\
\hline & Primary education & 0 & 0.00 & 2 & 20.0 & & \\
\hline & Preparatory education & 3 & 12.5 & 0 & 0.00 & & \\
\hline & Secondary education & 1 & 4.20 & 0 & 0.00 & & \\
\hline & University & 10 & 41.7 & 2 & 20.0 & & \\
\hline \multirow{3}{*}{ Marital state } & Single & 12 & 50.0 & 6 & 60.0 & \multirow{3}{*}{1.88} & \multirow{3}{*}{0.389} \\
\hline & Married & 10 & 41.7 & 2 & 20.0 & & \\
\hline & Divorced & 2 & 8.30 & 2 & 20.0 & & \\
\hline \multirow{3}{*}{ Occupation } & Employed & 3 & 12.5 & 0 & 0.00 & \multirow{3}{*}{2.06} & \multirow{3}{*}{0.356} \\
\hline & Unemployed & 19 & 79.2 & 8 & 80.0 & & \\
\hline & Worker & 2 & 8.30 & 2 & 20.0 & & \\
\hline \multirow{4}{*}{$\begin{array}{l}\text { Diseases } \\
\text { duration / years }\end{array}$} & $<1$ year & 6 & 25.0 & 4 & 40.0 & \multirow{4}{*}{10.8} & \multirow{4}{*}{ 0.012* } \\
\hline & $1-2$ years & 6 & 25.0 & 4 & 40.0 & & \\
\hline & $2-5$ years & 0 & 0.00 & 2 & 20.0 & & \\
\hline & $>5$ years & 12 & 50.0 & 0 & 0.00 & & \\
\hline \multirow{2}{*}{ Family history } & Yes & 10 & 41.7 & 4 & 40.0 & $\mathrm{FE}=$ & \multirow{2}{*}{1.00} \\
\hline & No & 14 & 58.3 & 6 & 60.0 & 0.008 & \\
\hline \multirow{2}{*}{$\begin{array}{l}\text { Compliance to } \\
\text { medication }\end{array}$} & Yes & 12 & 50.0 & 4 & 40.0 & \multirow{2}{*}{$\begin{array}{c}\mathrm{FE}= \\
0.283\end{array}$} & \multirow[b]{2}{*}{0.715} \\
\hline & No & 12 & 50.0 & 6 & 60.0 & & \\
\hline \multirow{3}{*}{$\begin{array}{l}\text { Number of } \\
\text { children }\end{array}$} & $1-2$ child & 9 & 37.5 & 2 & 20.0 & & \\
\hline & 2 -3 child & 3 & 12.5 & 2 & 20.0 & 1.07 & 0.585 \\
\hline & No children & 12 & 50.0 & 6 & 60.0 & 1.07 & 0.303 \\
\hline
\end{tabular}

FE: Fisher exact test **High significant *significant. 


\section{Discussion}

Depression is "a significant public health concern worldwide and has been ranked as one of the illnesses having the greatest burden for individuals, families, and society". "In recent years, complementary and alternative medicine (CAM) treatments have increased in popularity. This is especially true for treatments that are related to exercise and mindfulness-based interventions (MBIs) in the treatment of both mental and physical illness". Therefore, the purpose of this study was to evaluate the effectiveness of mindfulness training techniques on stress, anxiety, and depression of depressed patients. [1,19,24]

The present study revealed that there was highly statistically significant reduction in total mean score levels of anxiety and depression after mindfulness training

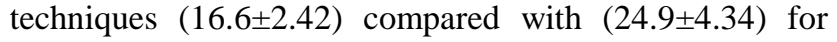
anxiety levels before training and (20.2 \pm 3.31$)$ compared with $(27.8 \pm 3.85)$ for depression levels before training (Table 2). Where $p$ value $(p=0.001)$; this could be due to the effect of mindfulness training techniques which involves self-regulation of attention and an orientation toward the present moment. It also activate specific emotion regulation skills and help patients shift their focus from a broad negativistic style of thinking to a more specific and present-focused style. The finding of the present study is similar to [38]; they conducted "a systematic review and meta-analysis regarding the effects of SAMs on symptoms of anxiety and depression. Systematic searching of electronic databases resulted in 18 eligible studies $(n=1150)$ for meta-analyses. After exclusion of one outlier SAMs had small to medium effects on anxiety (SMD $=0.39$; CI: 0.22, 0.56; PI: 0.07, 0.70; $<<.001$, I2 = 18.90\%) and on depression (SMD = 0.41; CI: 0.19, 0.64; PI: -0.05, 0.88; p < .001; I2 $=33.43 \%$ ), when compared with controls". So they concluded, that "Standalone mindfulness exercises have a small to medium effect on symptoms of anxiety and depression. It is noteworthy that mindfulness exercises are beneficial without being integrated in any larger therapeutic framework and that adverse events are rather unlikely".

Also, the finding of the existing study is parallel to [39]; they conducted "a literature search using PubMed, PsycINFO, the Cochrane Library, and manual searches. their meta-analysis was based on 39 studies totaling 1,140 participants receiving mindfulness-based therapy for a range of conditions, including cancer, generalized anxiety disorder, depression, and other psychiatric or medical conditions"; their results revealed that "mindfulness-based therapy was moderately effective for improving anxiety (Hedges' $\mathrm{g}=0.63$ ) and mood symptoms (Hedges' $\mathrm{g}=$ 0.59) from pre to post-treatment in the overall sample”. "In patients with anxiety and mood disorders, this intervention was associated with effect sizes (Hedges' g) of 0.97 and 0.95 for improving anxiety and mood symptoms, respectively”. These effect sizes were strong, unconnected to publication year or a number of management sessions, and were sustained over follow-up". These results suggest that "mindfulness-based therapy is a promising intervention for treating anxiety and mood problems in clinical populations”.
Regarding comparison of stress level total score before and after mindfulness training techniques, there was highly statistically significant reduction in total score of stress level after training (18.8 \pm 3.14$)$ compared with (27.1 \pm 4.37 ) before training (Table 2); this may be due to the effect of mindfulness meditation which involves slow and deep breathing in alleviating bodily symptoms of distress by balancing sympathetic and parasympathetic responses. Also experiencing the present moment none judgmentally and openly can effectively counter the effects of stressors; this result was in the same line with the study done by [40]; their findings suggest that "brief mindfulness training can help college students manage their stress in response to the universal academic and cognitive challenges of life".

Concerning correlation between depression and anxiety level of study group, the current finding revealed that there was "statistically significant positive correlation between them before intervention where p-value ( $p=0.019$ ), as e.g. when depression increases the anxiety will increase (Table 3); this could be due to that both emotional states (depression and anxiety) are associated with negative effect, stressful life events, impaired cognitive processes and share a common biological/genetic diathesis. The present finding was in the same line with the study done by [41]; who examined the "Effectiveness of Stress Management Program on Depression, Stress, and Anxiety of Depressed Patients"; their finding illustrated that "there was a positive relationship between depression and anxiety i.e. when depression increased the anxiety increased". Also, [42]; who assessed the“ Relationship Between Depression and Anxiety Symptoms: A Metaanalysis Study" they concluded that" Confidence intervals of 69 studies included in meta-analysis study were narrow, meaning that the decisions which will be made taking into consideration the data obtained from these studies are reliable. It has been found that depression has a positive effect on a wide range of anxiety. According to these findings, as depression levels increase, anxiety levels also increase, or as depression levels decrease, anxiety levels decrease. Overall, moderator variables of anxiety type, anxiety scale, and depression scale affect the relationship between depression and anxiety of individuals. Anxiety and depression levels can vary according to these moderator variables".

As regards to the correlation between depression and stress level of the study group, the existing study revealed that "there is a statistically significant positive correlation between them before and after intervention where p-value ( $p=0.015,0.013$ ), respectively”. As i.e. when depression level increases, stress level increase (Table 3).

The present finding was in the same line with [43]; their study assessed the "Relationship between the Onset of Depression and Stress Response Measured by the Brief Job Stress Questionnaire among Japanese Employees: A Cohort Study". The researchers concluded that "the stress response measured by the Brief Job Stress Questionnaire (BJSQ) can demonstrate a risk for the onset of depression”. Also, current result was in the consistent with study done by [41]; who examined the "Effectiveness of Stress Management Program on Depression, Stress, and Anxiety of Depressed Patients"; their result revealed that "there 
was positive relation between depression and stress i.e. when depression increased stress increased”.

Regards socio-demographic characteristics the existing study discovered that" there is no statistically significant relationship between depression and demographic feature such as; gender, educational level , marital status and occupation (Table 6), this result indicate that marital status ,occupation, educational difference and gender difference had no significant effect on depression; This may be due to decrease sample size. This outcome was congruent with [44]; the researchers indicated that "there was no significant statistical relation between demographic features such as; gender, education level, marital status and occupation". Also, [45] reported that "educational difference and occupation had no significant effect on depression". On the other hand; [46] their finding illustrated that "low educational levels were significantly associated with depression”. Also, [47] found that "Women suffer more from both types of depression than men". Moreover, [48]; their study's results showed that "women reported significantly more depressive symptoms than men, and, moreover, the gender gap widens with rising age (50-54: difference of 0.85 symptoms; 80-84: difference of 1.05 symptoms)”. This contradiction may be due to the presence of main risk factors for depression as genetic factors, biochemical factors, comorbidity, and ineffective life style.

Also, the current finding revealed that there is no statistically significant relationship between depression and age (Table 6); this could be due to genetic and biochemical influences that triggering depression. This finding was in the same line with [49] their study's result revealed that "Age was not correlated with depression $(\mathrm{r}=-0.01, \mathrm{p}=0.85)$ ". Contradict to this finding [41]; her study's result revealed that "there was a highly statistically significant relationship between depression and age"; this contradiction may be due to sampling size differences in these studies. Those contradictions in those studies indicate that the relationship between age and depression is U-shaped.

The present finding revealed that there is a highly statistically significant relationship between anxiety and gender difference of study participants after mindfulness training techniques, where $\mathrm{p}=0.004$ (Table 5). This may be due to "gender differences in physiological hyper-arousal, catastrophic cognitions and a general level of anxiety in a non-clinical population". This result was supported by [45]; found that "there was a statistically significant difference between gender and total anxiety score" Contradicted to this result; [41]; who studied "The Effectiveness of Stress Management Program on Depression, Stress, and Anxiety of Depressed" their result revealed that "there was no statistically significant relationship between anxiety and sex". This contradiction may be due to the difference in sample size. Also, the present finding revealed that there is a highly statistically significant relation anxiety and the number of children of study participants after mindfulness training techniques, where $p=0.008$ (Table 5); this may be due to the burden of life and several requirements of children. Concerning marital status and compliance to medication of the study group, the existing finding revealed that there is statistically significant relation between them and anxiety after mindfulness training techniques where $(\mathrm{p}=0.012$, 0.011 ) respectively (Table 5); this result was in the same line with [50] and [45]; their study's results revealed that "there was a statistically significant relation between marital status and anxiety" Contradicted to this result [41]; the researcher found that "there were no statistically significant relation between anxiety and (marital status \& compliance to medication)". This contradiction may be due difference in sample size.

As regards the relationship between stress and socio-demographic characteristics such as age, marital status, and the number of children of the study group, the present study revealed that there is a highly statistically significant relationship between them and stress level after mindfulness training techniques. Where $(\mathrm{p}=0.006,0.001$, and 0.001 respectively) (Table 4); this may be due to "the susceptibility to stress differs from person to person. Among the factors that influenced the vulnerability to stress are genetic vulnerability, coping style, type of personality and social support"; this result was supported by [41]; the researcher found that there" were highly statistically significant relationship between stress and marital status of depressed patients”, On the contrary [51]; who examined the "Effect of nursing intervention on stress and psychological wellbeing among university nursing students" the researcher found that there was no statistically significant relation between stress and (age, family number, marital status and income) of the study group before and after nursing intervention”. This may be due to the different of study subject or due to decreased sample size.

As regards marital status and compliance with medication, the existing study revealed that there is a highly statistically significant relationship between them and stress level. Where $\mathrm{p}=0.001$ and 0.009 , respectively, (Table 4) this result was supported by [41]; their study's result showed that "there were highly statistically significant relation between stress in relation to marital status and compliance”.

\section{Conclusion}

The implementation of mindfulness training techniques with depressed patients has a positive effect on reducing stress, anxiety, and depression levels.

\section{Recommendation}

This study recommended that application of mindfulness training techniques for all patients with depression to reduce their stress, anxiety, and depression levels.

\section{References}

[1] Bro, M. (2015). Mindfulness-based interventions as a treatment for depression. A literature review.

[2] World Health Organization. (2017). Depression and other common mental disorders: global health estimates (No. WHO/MSD/MER/2017.2). World Health Organization.

[3] Williams, M., Teasdale, J., Segal, Z. \&Kabat -Zinn, J. 2010. Mindfulness-based cognitive therapy reduces overgeneral 
autobiographical memory in formerly depressed patients. Journal of Abnormal Psychology.

[4] Lu, S. (2015). Mindfulness holds promise for treating depression. Monitor on psychology, 46(3), 50.

[5] Forkmann, T., Brakemeier, E., Teismann, T., Schramm, E., \& Michalak, J. (2016). The effects of Mindfulness-based Cognitive Therapy and Cognitive Behavioral Analysis System of Psychotherapy added to treatment as usual on suicidal ideation in chronic depression: Results of a randomized-clinical trial. Journal of Affective Disorders, 51-57.

[6] Chiesa A, Serretti A. Mindfulness-based interventions for chronic pain: a systematic review of the evidence. J Altern Complement Med. 2011; 17(1): 83-93.

[7] Edenfield, T. M., \&Saeed, S. A. (2012). An update on mindfulness meditation as a self-help treatment for anxiety and depression. Psychology research and behavior management, 5, 131.

[8] Ignácio, Z. M., da Silva, R. S., Plissari, M. E., Quevedo, J., \&Réus, G. Z. (2019). Physical Exercise and Neuro-inflammation in Major Depressive Disorder. Molecular neurobiology, 1-13.

[9] Al Bahnasy, R. A., Abdel-Rasoul, G. M., Mohamed, O. A., Mohamed, N. R., \&Ibrahem, R. A. (2013). Prevalence of depression, anxiety, and obsessive-compulsive disorders among secondary school students in Menoufia Governorate, Egypt. Menoufia Medical Journal, 26(1), 44.

[10] El-Wasify, Mahmoud A.; El-Boraie, Osama A.; El-Atrony, Mohammed H.; Abdel-Fatah, Abdel-Hady G, et al. The Prevalence and Correlates of Common Mental Disorders in Dakahlia Governorate (Egypt).Egypt. J. Neuro. Psych. Neurosur. 2011; 48: 4: 375-38.

[11] Amir M, El Gillany A self-reported depression and anxiety by students at an Egyptian Medical School. J Pak Psychiatr. Soc 2010; 7: 71 .

[12] Falsafi, N. (2016). A randomized controlled trial of mindfulness versus yoga: Effects on depression and/or anxiety in college students. Journal of the American Psychiatric Nurses Association, 22, 483-497.

[13] Sipe, W. E. B. \&Eisendrath, S. J. 2012. Mindfulness-Based Cognitive Therapy: Theory and Practice. The Canadian Journal of Psychiatry. Vol 57, No 2, February 2012. Accessed on 7th August 2014.

[14] Mindfulness Training as a Clinical Intervention: A Conceptual and Empirical Review, by Ruth A. Baer, http://www.wisebrain.org/papers/MindfulnessPsyTx.pdf.

[15] Kabat-Zinn, J. (2013). Full Catastrophe Living: Using the Wisdom of Your Body and Mind to Face Stress, Pain, and Illness. New York: Bantam Dell. ISBN 978-0345539724.

[16] Lutz, Antoine; Davidson, Richard J.; Slagter, Heleen A. (2011). "Mental Training as a Tool in the Neuroscientific Study of Brain and Cognitive Plasticity". Frontiers in Human Neuroscience. 5: 17.

[17] Gary Deatherage (1975). "The clinical use of "mindfulness" meditation techniques in short-term psychotherapy" (PDF). Journal of Transpersonal Psychology. 7 (2): 133-43.

[18] U.S. Department of Veterans Affairs, Office of Public Health. (2011, July). Mindfulness exercise. from http://www.publichealth.va.gov/.

[19] Hassan H., Hassan S., Baraka M. A Survey of Relationship between Duration of Infertility and Depression among Infertile Women in Beni Suef Governorate. International Journal of Science and Research, 2015; 4(10): 1170-1177

[20] Www.Beinghappybydesign.com. (2015). Depression Definition. Definition, mental health problem, suffering from depression. May 16. 2015.

[21] Hassan, H., Bayoumi, M., \& Atwa, A. Emotional Distress Associated with Gynecologic and Breast Cancer in Beni-Suef City. International Journal of Science and Research, 2016; 5(2): 1118-1129.

[22] Nasr E., Hassan H., Sheha E. Psychological Consequences of Hypertensive Disorders among Pregnant Women. Scientific Research Journal, 2016; 4(9): 1-8.

[23] Hassan H. Infertility profile, psychological ramifications and reproductive tract infection among infertile women, in northern Upper Egypt. Journal of Nursing Education and Practice. 2016; 6(4): 92-108.

[24] Hassan, H., Sheha, E., \& Nasr, E. Level of Stress Among Pregnant Women with Heart Problems. International Journal of Research-GRANTHAALAYAH, 2016; 4(7): 220-230.
[25] Hassan H. Effectiveness of a structured teaching program on anxiety and perception regarding toxoplasmosis among seropositive pregnant women in Northern Upper Egypt. Clinical Nursing Studies. 2018; 6(1): 1-19.

[26] Hassan H., Said S., Hassanine Sh. Disparities of Prevalence and Causes of Maternal Antenatal Anxiety among Primigravida Pregnant Women in Egypt. American Research Journal of Nursing. 2017; 3(1): 1-15.

[27] Hassan H., Saber N., Sheha E. Comprehension of Dyspareunia and Related Anxiety among Northern Upper Egyptian women: Impact of Nursing Consultation Context Using PLISSIT Model. Nursing \& Care Open Access Journal. 2019; 6(1): 1-19.

[28] Hassan H., Ahmed W., Mahmoud A. Impact of Tailored Educational Program on Primigravida Anxiety and Knowledge Regarding Minor Discomforts in Upper Egypt. International Journal of Studies in Nursing. 2020; 5(1): 1-16.

[29] Gamel W., Hassan H., El-ezazy A. Male Infertility and Psychological Repercussions: A Neglected Problem in Northern Upper Egypt. International Journal of Studies in Nursing, 2019; 4(4): 1-26.

[30] Page, C., Hooke, R., \& Morrison, L. (2007). Psychometric properties of the Depression Anxiety Stress Scales (DASS) in depressed clinical samples. Br J Clin Psychol, 46, 283-297.

[31] Hassan H. Call for psychosocial well-being among pregnant women associated with medical disorder in Beni-Suef governorate. IOSR Journal of Nursing and Health Science. 2016; 5(2): 81-94.

[32] Nasr E., Hassan H., Sheha E. Psychological Consequences of Hypertensive Disorders among Pregnant Women. Scientific Research Journal, 2016; 4(9): 1-8.

[33] Hassan H., Mohamed A., Ibrahim M. Depression Symptoms among Diabetic Pregnant Women in Beni-Suef. International Journal of Science and Research, 2016; 5(5): 7-12.

[34] Parkitny L. \& McAuley J. The Depression Anxiety Stress Scale (DASS). Journal of Physiotherapy. 2010; 56 (3): 204. http://www2.psy.unsw.edu.au/dass/over.htm

[35] Lovibond, S.H. \&Lovibond, P.f. Manual for the Depression Anxiety Stress Scales. (2nd Ed) Sydney: Psychology Foundation. 1995.

[36] Kotb F. Social support, psychological distress and suicidal tendency of depressed patient. Unpublished master thesis. Faculty of nursing, Cairo University. 2007: 170-172.

[37] Kabat-zinn, j. (1990). Full catastrophe living. The wisdom of your body and mind to face stress, pain and illness. New york, NY: Bantam Doubleday Dell Publishing.

[38] Blanck, P., Perleth, S., Heidenreich, T., Kröger, P., Ditzen, B., Bents, H., \&Mander, J. (2018). Effects of mindfulness exercises as stand-alone intervention on symptoms of anxiety and depression: Systematic review and meta-analysis. Behavior research and therapy, 102, 25-35.

[39] Hofmann, S. G., Sawyer, A. T., Witt, A. A., \& Oh, D. (2010). The effect of mindfulness-based therapy on anxiety and depression: A meta-analytic review. Journal of consulting and clinical psychology, 78(2), 169.

[40] Shearer, A., Hunt, M., Chowdhury, M., \&Nicol, L. (2016). Effects of a brief mindfulness meditation intervention on student stress and heart rate variability. International Journal of Stress Management, 23(2), 232.

[41] Maaly. I. El Malky ,Merfat. M. Atia,Sabah. H. El-Amrosy (2015). The Effectiveness of Stress Management Programme on Depression, Stress, and Anxiety of Depressed Patients.Journal of Nursing Science. 1(2): 15-24.

[42] Karadag, E., \&Solpuk, N. (2018). Relationship Between Depression and Anxiety Symptoms in studies Conducted in Turkey: A Meta-analysis Study. DUSUNEN ADAM-JOURNAL OF PSYCHIATRY AND NEUROLOGICAL SCIENCES, 31(2), 163-176.

[43] Wada, K., Sairenchi, T., Haruyama, Y., Taneichi, H., Ishikawa, Y., \& Muto, T. (2013). Relationship between the onset of depression and stress response measured by the Brief Job Stress Questionnaire among Japanese employees: a cohort study. PLoS One, 8(2), e56319.

[44] Moghadam, M. B., Moghadam, A. B., \&Salehian, T. (2015). Efficacy of Eye Movement Desensitization and Reprocessing (EMDR) on depression in patients with Myocardial Infarction (MI) in a 12-month follow up. Iran J Crit Care Nurs, 7(4), 221-226. 
[45] Mona Abd EL Reheem El Nager\& Sabah Hassan El-Amrosy (2019); For education as a factor in depression, the result of the present study showed that education difference had no significant effect. This may be due to the lowest sample size.

[46] Farahani, H. A. Comparing Anxiety, Depression and Sexual Life Satisfaction in Two Groups of Fertile and Infertile Women in Tehran. J. Repro. Infer. 2006; 12(4).

[47] Akhtar-Danesh, N., \&Landeen, J. (2007). Relation between depression and sociodemographic factors. International journal of mental health systems, 1(1), 4.

[48] Buber, I., \&Engelhardt, H. (2011). The association between age and depressive symptoms among older men and women in Europe. Findings from SHARE. Comparative Population Studies, 36(1).
[49] Weiss Wiesel, T. R., Nelson, C. J., Tew, W. P., Hardt, M., Mohile, S. G., Owusu, C., ... \& Ramani, R. (2015). The relationship between age, anxiety, and depression in older adults with cancer. Psycho-Oncology, 24(6), 712-717.

[50] Khamoushi, F., Ahmadi, S. M., Karami-Matin, B., AhmadiJouybari, T., Mirzaei-Alavijeh, M., Ataee, M., \& Mahboubi, M. (2015). Prevalence and socio-demographic characteristics related to stress, anxiety, and depression among patients with major thalassemia in the Kermanshah County. J BiolTodey's World, 4(3), 79-84.

[51] Maaly. E. Elmalky, Gehan. A. Abed, Merfat. M. Atia, Elham. R. Elfiky (2019). Effect of nursing intervention on stress and psychological wellbeing among university nursing students. International Journal of Novel Research in Healthcare and Nursing Vol. 6, Issue 3, pp: (39-51), Month: September - December 2019, Available at: www.noveltyjournals.com.

(C) The Author(s) 2020. This article is an open access article distributed under the terms and conditions of the Creative Commons Attribution (CC BY) license (http://creativecommons.org/licenses/by/4.0/). 